\title{
Anisotropic Au-ZnO photocatalyst for the visible-light expanded oxidation of n-hexane
}

\author{
Carlos J. Bueno-Alejo ${ }^{a, b}$, Javier Graus ${ }^{a}$, Raul Arenal ${ }^{* a, d, e, f}$, Marta Lafuente ${ }^{a, b}$, Bruno \\ Bottega-Perghera ${ }^{a}$ Jose L. Hueso ${ }^{* a, b, c, d}$
}

${ }^{a}$ Institute of Nanoscience of Aragon (INA), Campus Rio Ebro, 50018, Zaragoza, Spain

${ }^{b}$ Department of Chemical and Environmental Engineering, Campus Rio Ebro, 50018, Zaragoza, Spain

${ }^{c}$ Networking Research Center on Bioengineering, Biomaterials and Nanomedicine (CIBERBBN), 28029, Madrid, Spain

${ }^{d}$ Instituto de Ciencia de Materiales de Aragon (ICMA), Consejo Superior de Investigaciones Científicas (CSIC-Universidad de Zaragoza), Zaragoza, Spain

${ }^{e}$ ARAID Foundation, 50018 Zaragoza, Spain

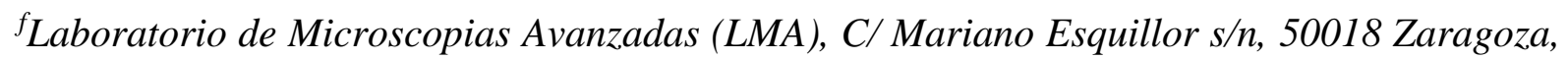
Spain

*Corresponding authors. E-mail: jlhueso@unizar.es (Jose L. Hueso); arenal@unizar.es (Raul Arenal)

KEYWORDS: Photocatalysis; Plasmonics; EELS; Heterostructures; Gold; Zinc oxide; VOCs oxidation 


\begin{abstract}
In this work we present a novel metal-semiconductor heterostructure that contains triangular and prism-shaped plasmonic gold nanostructures directly synthesized and assembled onto $\mathrm{ZnO}$ nanostructures. Spatially-resolved (SR) high-resolution electron energy loss spectroscopy (EELS) at the local (sub-nanometer scale) level confirmed the field enhancement of the local electromagnetic fields in the surroundings of the triangular and prism-shaped $\mathrm{Au}$ nanostructures and in the interfacial junction between $\mathrm{Au}$ and $\mathrm{ZnO}$. Different LED excitation sources have been systematically selected in the whole UV-VisNIR range to evaluate the photocatalytic response of the $\mathrm{Au}-\mathrm{ZnO}$ heterostructures towards the oxidation of n-hexane, selected as a model VOC present in indoor environments. The $\mathrm{Au}-$ $\mathrm{ZnO}$ exhibits visible expanded photo-response with the more energetic interband and intraband electrons and the higher LED irradiation wavelengths and it is able to outperform its $\mathrm{ZnO}$ plain counterpart.
\end{abstract}

\title{
1. INTRODUCTION
}

The Intergovernmental Panel on Climate Change (IPCC) of the United Nations is demanding urgent changes in the energy production policies of developed countries towards cleaner and environmentally sustainable alternatives that can alleviate the current pollution levels [1]. The use of fossil fuels must be progressively abandoned and substituted by novel and competitive technologies that embrace the respect to our environment and apply circular economy principles [1]. One of the major concerns derived from the current anthropogenic activities is related with the emission of hazardous gases such as nitrogen oxides $\left(\mathrm{NO}_{\mathrm{x}}\right)$, soot particles or volatile organic compounds (VOCs) [2-9]. These elements can not only contribute to global warming as greenhouse effect gases, but also induce harmful diseases and odors in populated and industrialized regions with high levels of pollution. VOCs can be 
additionally generated in indoor scenarios from a wide variety of sources (solvents, cooking, smoke) $[1,3]$.

Photocatalysis has emerged as a clean and sustainable alternative to mitigate VOCs and other pollutants emissions with the aid of different natural or artificial irradiation sources [10-14]. The use of semiconductors that can induce the generation of electron-hole pairs under irradiation as active species to react with molecules has been intensively studied, especially for the case of $\mathrm{TiO}_{2}$. The remediation of VOCs in the presence of $\mathrm{TiO}_{2}$ has been especially applied in wastewater treatments $[2,3,15]$. Recent studies have claimed about the difficulties to extrapolate the integration of effective systems for gas-phase photocatalytic treatment of polluted air in large areas [15]. Further research is still necessary to implement disruptive improvements that can pave the way for the regular use of solar light and/or low consumption artificial lights (i.e. Light-emitting diodes-LEDs, novel reactor configurations and so on) $[9,10,12-14,16-25]$. In addition, it is also necessary to boost the development of novel photocatalytic materials that can overcome the inherent burdens of $\mathrm{TiO}_{2}$ and are able to take advantage of the full solar spectrum instead of the limited UV range attributed to $\mathrm{TiO}_{2}$ [26-34].

In this regard, the coupling of metal-semiconductor heterostructures has become a promising strategy to generate new photocatalysts since metal nanoparticles such as gold, silver, copper or aluminum can expand the light absorption range of semiconductors $[26,28$, 35-39]. Likewise, these metallic nanostructures can greatly enhance the photocatalytic activity of regular semiconductors given their plasmonic properties that facilitate the effective transport of hot carriers (i.e. hot electrons or hot holes) [26-29, 39-49]. Another important topic of interest is currently devoted to the search for valid alternatives to $\mathrm{TiO}_{2}$ as semiconductor photocatalytic supports. Zinc oxide $(\mathrm{ZnO})$ has been explored in the past years due to its similarities with $\mathrm{TiO}_{2}$ in terms of electron affinity, wide band gap, fast carrier 
mobility, large scale synthesis capability or induced shape anisotropy to facilitate charge transport (i.e. prolonged carrier lifetimes) [50-57]. Unfortunately, $\mathrm{ZnO}$ also exhibits some of the inherent drawbacks of $\mathrm{TiO}_{2}$ such as low degree of charge carrier separation and restricted photoresponse to the solar spectrum [57]. For these reasons, recent studies have explored the synergetic combination of plasmonic $\mathrm{Au}$ and $\mathrm{ZnO}$ structures to form metal-semiconductor heterojunctions $[39,50-58]$. Au- $\mathrm{ZnO}$ hybrids with different shapes and configurations have been systematically investigated and preferentially applied to UV-visible-expanded photocatalytic degradation of organic pollutants or model dyes in liquid media $[39,52,56-$ 62]. Furthermore, these $\mathrm{Au}-\mathrm{ZnO}$ composites have been also successfully tested in photoassisted gas phase reactions for sensing [63], hydrogen production [64] or $\mathrm{CO}_{2}$ hydrogenation [65].

Herein, we present the synthesis of a hybrid photocatalyst containing anisotropic gold nanostructures (mostly nanoprisms and nanotriangles) in situ generated onto $\mathrm{ZnO}$ semiconductor nanoparticles. Spatially-resolved (SR) high-resolution electron energy loss spectroscopy (EELS) at the local (sub-nanometer scale) level in combination with additional Finite-Difference-Time-Domain (FDTD) theoretical calculations confirmed the field enhancement of the local electromagnetic fields in the surroundings of the triangular and prism-shaped $\mathrm{Au}$ nanostructures and in the interfacial junction between $\mathrm{Au}$ and $\mathrm{ZnO}$. The photocatalytic performance of the catalyst was systematically evaluated upon irradiation with different LED wavelengths towards the gas-phase photo-oxidation of n-hexane. We have been able to establish a positive photo-oxidation capability of the $\mathrm{Au}-\mathrm{ZnO}$ composite beyond the UV active region of the semiconductor. 


\section{EXPERIMENTAL}

\subsection{Chemicals}

Zinc oxide ( $\geq 99 \%$ ), gold (III) tetrachloroauric acid hydrate $(99.9 \%, \sim 50 \%$ Au basis), sodium citrate tribasic dihydrate $(\geq 99 \%)$, sodium borohydride $\left(\mathrm{NaBH}_{4}, \geq 99.0 \%\right)$ were purchased from Sigma-Aldrich and used without any further purification.

\subsection{Synthesis of the Au-ZnO photocatalyst}

The synthesis of the $\mathrm{Au}-\mathrm{ZnO}$ was carried out as described elsewhere [35, 62]. The standard procedure can be briefly described as follows: in the first place, $1 \mathrm{~g}$ of $\mathrm{ZnO}$ was dispersed in $40 \mathrm{~mL}$ of distilled water and $\mathrm{pH}$ adjusted to 12.5 with the aid of $\mathrm{NaOH}(1 \mathrm{M})$ during 15 minutes with continuous stirring. Then, $20 \mathrm{mg}$ of the gold precursor $\left(\mathrm{HAuCl}_{4}\right)$ suspended in $3 \mathrm{~mL}$ of water was added dropwise to the $\mathrm{ZnO}$ basic suspension. After that, 23.5 mg of sodium citrate previously dissolved in $2 \mathrm{~mL}$ DI water were added and left stirring for 15 additional minutes. Finally, a freshly prepared aqueous solution of $\mathrm{NaBH}_{4}(3.8 \mathrm{mg}$ in $5 \mathrm{~mL}$ of DI water) was added to induce the reduction of the gold precursor and stirred during 40 minutes. After completing the reduction, the system was filtered with warm water $\left(\sim 60{ }^{\circ} \mathrm{C}\right)$ and dried overnight at a similar temperature. The synthesis of the nanomaterials has been performed by the Platform of Production of Biomaterials and Nanoparticles of the NANOBIOSIS ICTS, more specifically by the Nanoparticle Synthesis Unit of the CIBER in BioEngineering, Biomaterials \& Nanomedicine (CIBER-BBN).

\subsection{Characterization techniques}

The morphologies and particle size distributions were determined by transmission electron microscopy (TEM) (FEI Tecnai T20, operating at $200 \mathrm{kV}$ ). The high-resolution TEM images were obtained in a Titan (FEI TITAN ${ }^{3}$, operated at $300 \mathrm{kV}$ and equipped with a Gatan Image 
Filter (GIF Tridiem 863)). TEM sample were prepared by dispersing the raw synthesized powder in ethanol and sonicating it. One drop of the suspension was deposited on a holey carbon coated copper grid for the TEM analyses. High-Angle Annular Dark Field (HAADF)Scanning Transmission Electron Microscopy (STEM) and electron energy loss spectroscopic (EELS) data were recorded using a probe-corrected FEI Titan Low-Base 60-300 kV STEM equipment, operated at $120 \mathrm{kV}$ and equipped with a Cs probe corrector, a high-brightness XFEG gun, a monochromator and a Gatan Tridiem 866 ERS energy filter. 15 EEL spectra (of $10 \mathrm{~ms} / \mathrm{each}$ ) were acquired for each probe position following a two-dimensional (2D) region across the nanostructures. The convergence and collection angle were 25 and $35 \mathrm{mrad}$, respectively. Typical energy resolutions (full-width at half-maximum of the zero-loss peak (ZLP)) of the measurements were better than $180 \mathrm{meV}$. EEL spectra were acquired using the spectrum-imaging (SPIM) mode [66, 67]. For the data analysis, each EEL spectrum was aligned along the ZLP and the tail of the zero-loss peak was removed using a power law subtraction method. After that, we have employed a multivariate decomposition technique, non-negative matrix factorization (NMF) [68] to extract the optical response of these nanoobjects. UV-Vis spectroscopy (V-67, Jasco Company) equipped with an integrated sphere accessory was used to analyze the absorbance spectra of the nanomaterials.

\subsection{Finite-difference time-domain simulations}

The electric field distribution over the $\mathrm{Au}-\mathrm{ZnO}$ catalyst was simulated by the finite-difference time-domain (FDTD) method (Lumerical Solution Inc., FDTD solutions). The simulation model used was gold nanotriangles with and edge of $25 \mathrm{~nm}$ and 5, 10 or $15 \mathrm{~nm}$ of thickness over the $\mathrm{ZnO}$ support. The dimensions of the gold nanotriangles were determined from the HR-TEM images and represent the major populations of nanoparticles. Conformal mesh and mesh refinement were used to define the structure with a minimum mesh size of $0.1 \mathrm{~nm}$. A plane wave propagating in the $z$-direction with an electric field parallel to the $x$-direction was 
selected to estimate the electric field distribution. The values of the dispersion relation for $\mathrm{Au}$ and $\mathrm{ZnO}$ were extracted from the literature $[69,70]$. The spatial distribution of the electric field over the $\mathrm{Au}-\mathrm{ZnO}$ catalyst was simulated under the wavelength used in the catalytic reaction: $365 \mathrm{~nm}, 405 \mathrm{~nm}$ and $460 \mathrm{~nm}$.

\subsection{LED-assisted n-hexane photo-oxidation tests}

The photocatalytic reaction was performed in a home-made system comprising a quartz rectangular cell $(50 \times 10 \times 2 \mathrm{~mm}$ (height $\times$ width $\times$ length) purchased from Teknokroma) [13]. The cell was illuminated by two high power LEDs (LedEngin) coupled to Synjet® cooling system placed at $1 \mathrm{~mm}$ from the cell wall in order to maximize the irradiation of the whole bed of catalyst. Different wavelength and output powers were used to study the behaviour of the catalyst under UV and visible irradiation: $365 \mathrm{~nm}(4.5 \mathrm{~W}), 405 \mathrm{~nm}(3.9 \mathrm{~W})$ and $460 \mathrm{~nm}(2.2 \mathrm{~W})$. Different irradiances up to $9 \mathrm{~W} \cdot \mathrm{cm}^{-2}$ were tested tuning the LED output with the aid of a programmable power supply unit (ISO-TECH, IPS-405, 0-40V). The temperature of the catalytic bed containing $200 \mathrm{mg}$ of the photocatalysts during irradiation was monitored with the aid of a K-type thermocouple placed in the middle of the bed of catalyst. A flow-rate feed of $25 \mathrm{~mL} \cdot \mathrm{min}^{-1}$ was used containing $200 \mathrm{ppm}$ of $\mathrm{n}$-hexane. In order to obtain the final concentration in the inlet was required the mixing with the proper flow rates of n-hexane in $\mathrm{N}_{2}, \mathrm{O}_{2}$ and synthetic air (purchased from PRAXAIR España S.L.U., Madrid, Spain). After an equilibration period of $30 \mathrm{~min}$ that served us to evaluate the dark adsorption of n-hexane in the catalyst, the LED lights were turned on for different time intervals and the gas effluent outlet analyzed by gas chromatography (Agilent 3000 Micro GC). Two modules with OV-1 and PPQ columns, each one of them attached to a thermal conductivity detector (TCD), were employed to separate and detect the different gas compounds. The steady state final concentration achieved was $10 \mathrm{ppm}$ of $\mathrm{n}$-hexane when maximum LED power was used. This steady state was always achieved within minutes 
regardless of the experimental settings. Accumulated irradiation cycles of the same catalyst did not lead to deactivation. The n-hexane detection limit was $3 \mathrm{ppm}$ and $\mathrm{CO}_{2}$ was the only oxidation by-product detected in the outlet. Maximum error in the mass balance closures for carbon and oxygen in this work was $2 \%$.

\section{RESULTS AND DISCUSSION}

\subsection{Characterization of the anisotropic Au-ZnO heteronanostructures}

Figure 1a-c show some representative TEM and HR-TEM images of the Au- $\mathrm{ZnO}$ hybrids and the preferential formation of triangular and prism-shaped Au nanostructures decorating the $\mathrm{ZnO}$. These anisotropic Au shapes are directly generated onto $\mathrm{ZnO}$ supporting NPs by an in situ reduction-deposition method that required the addition of sodium borohydride as reducing agent, sodium citrate as ligand stabilizer and sodium hydroxide to promote a highly alkaline reaction conditions $(\mathrm{pH} \sim 12.5)$. These basic conditions have been previously demonstrated to promote the preferential formation of anisotropic Au nanostructures [35, 62, 71]. This specific Au shapes have not been typically reported in the $\mathrm{Au}-\mathrm{ZnO}$ related literature since more attention has been normally paid to the modification of the $\mathrm{ZnO}$ anisotropy and the generation of core-shell like heterostructures [57, 58, 60, 65]. TEM images also reveal a good interfacial contact between the triangular shaped $\mathrm{Au}$ and the $\mathrm{ZnO}$ polymorphs. This is considered as an essential factor to ensure suitable carrier mobility upon illumination [57, 72]. The presence of Au nanostructures has been also reported as a positive parameter to prevent $\mathrm{ZnO}$ from photo-corrosion [57]. 

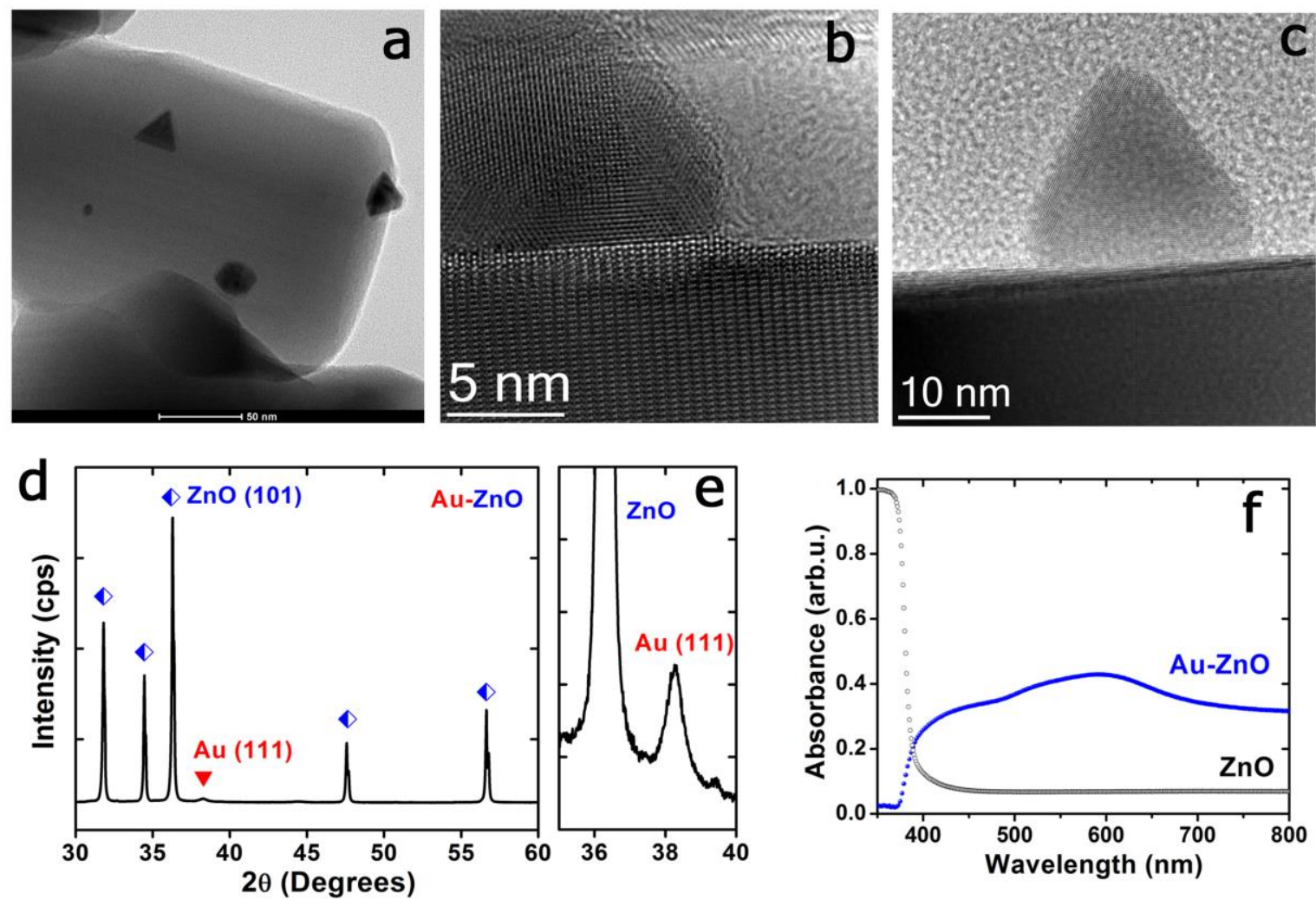

Figure 1. (a)-(c) Representative TEM and HR-TEM images of the Au-ZnO photocatalyst accounting for the presence of gold-based nanotriangles and prisms with good contact onto the $\mathrm{ZnO}$ semiconductor; (d) XRD patterns for the $\mathrm{Au}-\mathrm{ZnO}$ hybrid and their corresponding crystallographic assignations to hexagonal $\mathrm{ZnO}$ and cubic $\mathrm{Au}$ phases, respectively; (e) Zoomed in area accounting for the $\mathrm{Au}$ main diffraction peak; (f) UV-Vis spectra corresponding to the $\mathrm{ZnO}$ (black hollow dots) and the $\mathrm{Au} / \mathrm{ZnO}$ nanoparticles (blue filled dots), respectively.

Figure 1d confirms the crystalline structure of the $\mathrm{Au}-\mathrm{ZnO}$ hybrid. The diffraction pattern can be attributed to a hexagonal wurtzite-type structure for $\mathrm{ZnO}$ and a cubic phase for $\mathrm{Au}$ (see enlarged diffraction peak in Figure 1e). The UV-Vis spectra show a clear modification in the absorption spectrum of $\mathrm{ZnO}$ (Figure 1f). The in-situ growth and deposition of anisotropic Au nanostructures has expanded and broadened the absorption band towards the whole visible-NIR range. This red-shift can be attributed to the absorption capabilities of $\mathrm{Au}$ nanostructures [26] and their plasmonic behaviour [57]. The variety of sizes and shapes (triangles and prisms) [62] induces changes in the electromagnetic field at the surface of the NPs and a shift in the oscillation frequencies of the conduction electrons 
$[28,65,73]$. At the end, an almost continuous absorption band is measured as a combination of all these modifications in the Au nanostructures (Figure 1e).

In order to experimentally correlate the optical response of the plasmonic $\mathrm{Au}$ nanostructures at the interface with $\mathrm{ZnO}$ with the absorption properties at the local level (subnanometer scale), a spatially-resolved (SR) high-resolution electron energy loss spectroscopic (EELS) study was carried out [74-78]. Figure 2a shows the (HAADF)-STEM image of one of these $\mathrm{Au}-\mathrm{ZnO}$ nanospecimens. In this area, three $\mathrm{Au}$ nanoprisms are supported on the $\mathrm{ZnO}$ nanostructure. As we can observe, the selected Au prism (see green square marked region) is partially supported onto the $\mathrm{ZnO}$ substrate and the rest of the nanoprism is on vacuum. We have acquired an EELS spectrum-image (SPIM). Figure 2c displays the optical response of these objects, in particular the four spectral maps components obtained by applying nonnegative matrix factorization (NMF) to the EEL-SPIM.

The decomposition components are readily identified from the spatial distributions displayed in Figure $2 \mathrm{~b}$ and compare reasonably well with the calculated excitations. The two first components, noted as (i) and (ii), are governed by the plasmonic response (local plasmon resonances (LPR)) of the Au nanoparticle. The first component at $\sim 2.25 \mathrm{eV}(\sim 550 \mathrm{~nm})$ is partially delocalised across the faces of the entire structure and it could associated to the edge $\mathrm{Au}$ LPR, which is a multi-polar mode [79]. The second component, (ii) centered at $\sim 2.6 \mathrm{eV}$ $(\sim 475 \mathrm{~nm})$, exhibits losses concentrated at the free tip of the prism (this one that is not in contact with the $\mathrm{ZnO})$. This can be assigned to a dipolar LPR mode [79].

It is interesting to see that comparing with previous works on Au nanotriangles [79], these two modes are shifted in energy. This could be due to some coupling between the Au LPRs and the $\mathrm{ZnO}$ excitations (near band edge (NBE) onset and excitons) [80]. The third and 
fourth components are located at $\sim 3.5 \mathrm{eV}$ and $\sim 3.6 \mathrm{eV}(\sim 354-344 \mathrm{~nm})$. Both components should be associated to the NBE and excitons of $\mathrm{ZnO}[80]$. It seems that the observed blueshift of the NBE ( 200 meV) could be due to the effect of the interaction between the $\mathrm{ZnO}$ and the Au nano-triangle, and it could be associated to an energy transfer from the $\mathrm{ZnO} \mathrm{NBE}$ to the Au LPR as a result of the formation of a Schottky barrier or Ohmic contact [57]. This could also be confirmed by the spatial extension of these excitations (see Figure 2b-iii and iv) and suggest the formation of a $\mathrm{Au}-\mathrm{ZnO}$ heterojunction in accordance to previous examples available in the literature [57]. 

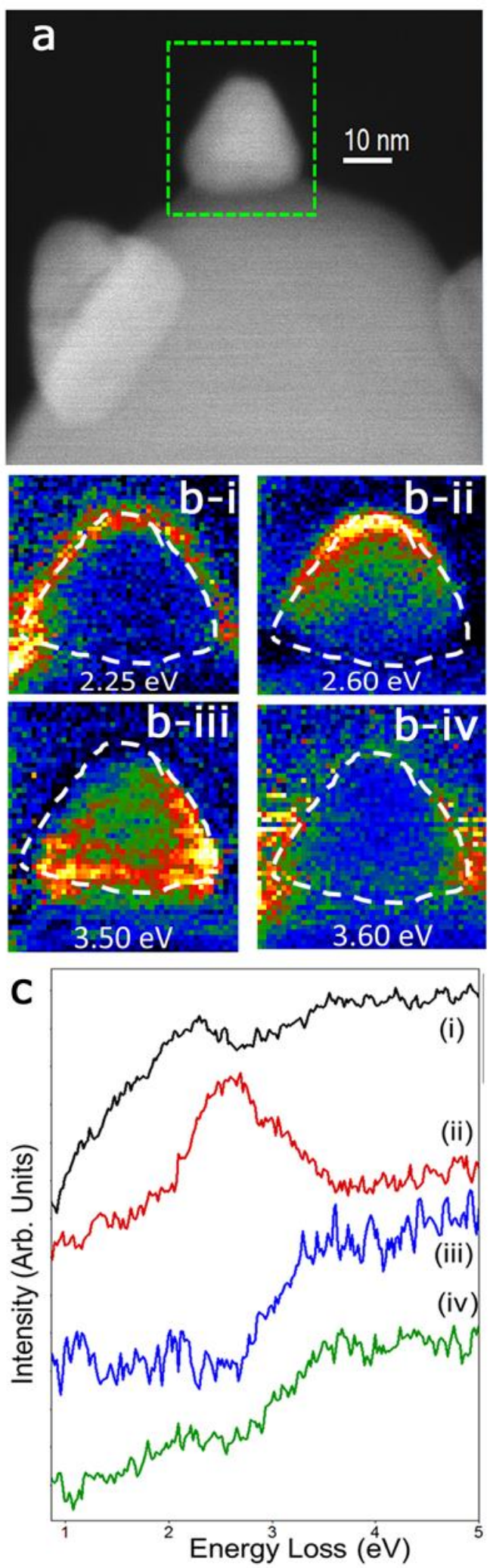

Figure 2. (a) HAADF-STEM image of a Au-ZnO nanosystem. An EELS SPIM has been acquired at the green marked area; (b) EELS decomposition components of the NMF analysis, showing the spatial distribution of the optical response of these nano-objects; (c) Representative EEL spectral components shown in (b). The different modes, from (i) to (iv), are displayed in this figure. 


\subsection{LED-driven photocatalytic oxidation of n-hexane}

The photocatalytic response of the Au-ZnO hybrid was evaluated towards the LEDassisted oxidation of n-hexane diluted in air, as a model indoor VOC compound with very limited reactivity in comparison with other aromatic counterparts [20, 81]. Different LED wavelengths were systematically tested from the UV to the NIR ranges, including a control series with plain $\mathrm{ZnO}$ nanoparticles. Likewise, photolysis influence by direct irradiation with the UV-LEDs in the absence of catalyst was previously tested and discarded $[13,82]$. Figure 3 shows the n-hexane photo-oxidation at increasing irradiances in the presence of the $\mathrm{Au}$ $\mathrm{ZnO}$ and $\mathrm{ZnO}$ catalysts, respectively. When irradiating with only UV-LED wavelengths at $365 \mathrm{~nm}$, up to $96 \% \mathrm{n}$-hexane conversion levels are achieved with irradiances below $3 \mathrm{~W} \cdot \mathrm{cm}^{-}$

${ }^{2}$. At this irradiation wavelength the photoactivity is clearly governed by the semiconductor support. Electron-hole pairs can be generated. These excitons are separated and the electrons can readily react with $\mathrm{O}_{2}$ molecules to form an active superanion radical $\left({ }^{\circ} \mathrm{O}^{2-}\right)$ in the Conduction Band (CB) of $\mathrm{ZnO}$ while the positive holes in the Valence Band (VB) remain available to react with VOC molecules $[13,82]$. The irradiation at $405 \mathrm{~nm}$ increased the conversion of $\mathrm{n}$-hexane to $>99 \%$ in the $\mathrm{Au}-\mathrm{ZnO}$ hybrid at the expense of increasing the irradiance 3 times in comparison with the UV-LED (Figure 3). The $\mathrm{ZnO}$ activity must be attributed to the partial fraction of UV light emitted within the $405 \mathrm{~nm}$ LED. Still, the influence of $\mathrm{Au}$ is important and predominant at all the irradiances explored. This effect becomes more evident using the $460 \mathrm{~nm}$ LEDs where $\mathrm{ZnO}$ exhibits negligible photoactivity (see Figure 3). In contrast, the $\mathrm{Au}-\mathrm{ZnO}$ composite reaches up to $36 \%$ of $\mathrm{n}$-hexane. It is also worth mentioning that no evidence of deactivation signs was observed after running multiple consecutive irradiation experiments with the same catalytic bed (more than 12 hours). Shifting from one LED to another also rendered analogous conversion levels, thereby accounting for a good stability of the photocatalyst, regardless of the irradiation wavelength. 


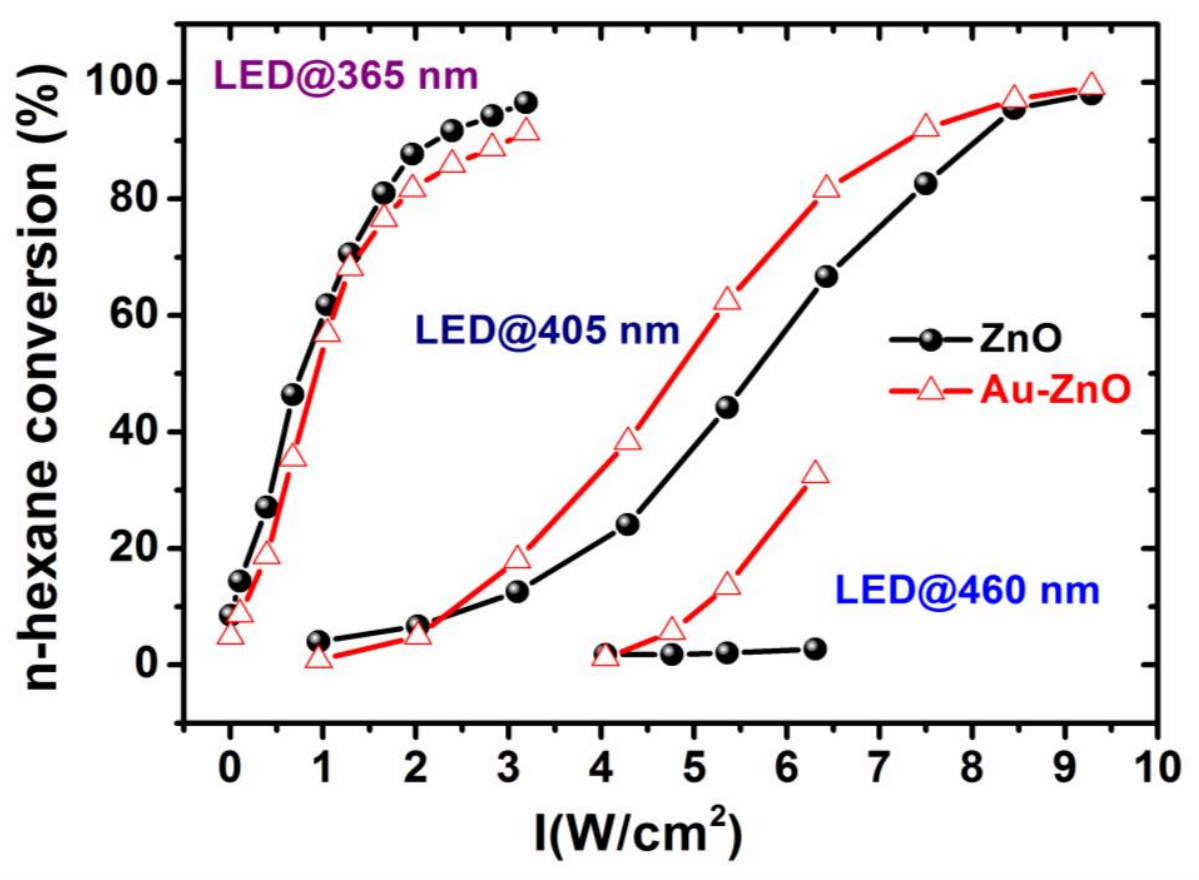

Figure 3. Evaluation of the photocatalytic response of $\mathrm{ZnO}$ and $\mathrm{Au}-\mathrm{ZnO}$ nanostructures towards the oxidation of n-hexane under different LED wavelengths and increasing irradiances.

There are two plausible explanations for the visible-expanded activity of the $\mathrm{Au}-\mathrm{ZnO}$ heterostructure. The first one is attributable to the formation of a Schottky barrier $(\sim 0.6 \mathrm{eV})$ between the support and the metal that facilitates not only the absorption of visible light, but also the separation of charges generated at the interface. The formation of this barrier would be sustained by previous results available in the literature and by the experimental values detected by SR-EELS for the LPR Au and NBE-ZnO energy levels, respectively (Figure 2b2c). The second explanation is the intraband electronic transition occurring in plasmonic gold nanoparticles as previously described by Sarina et al. [26]. In this mechanism when using blue light the electronic transition activated is not the typical interband transition but the one occurring within the same energy band (generally 6sp electrons). These 6sp electrons can be redistributed to energy levels above the Fermi level and either react themselves with 
$\mathrm{O}_{2}$ molecules or transfer to the $\mathrm{CB}$ of $\mathrm{ZnO}$, leaving a positive charge behind ready to react with n-hexane. All these reaction mechanisms are plausible and difficult to discern since the accommodation of the energy levels is strongly dependent on an abundant number of parameters including size, shape, interfacial metal-semiconductor connection and so on. Other mechanisms such as near-field local enhancement or the role of Au as electron traps can be in principle discarded in our particular system since the $\mathrm{Au}-\mathrm{ZnO}$ is not able to outperform the plain $\mathrm{ZnO}$ under UV-LED irradiation conditions. Otherwise, an enhanced performance would have been obtained upon these latter conditions. Remarkably, the use of LEDs irradiating at higher excitation wavelengths (i.e. 530 to $740 \mathrm{~nm}$ ) did not render any significant $n$-hexane conversion, regardless of the applied irradiances. In spite of the broad $\mathrm{UV}-\mathrm{Vis}$ absorption spectrum of the $\mathrm{Au}-\mathrm{ZnO}$ and the expected injection of hot electron at the LPR wavelengths (Figure 1f) only the more energetic electrons are able to induce photoactivity towards this specific pollutant. Analogous photoresponse with limited incidence of the LPR have been previously described in the literature in the photodegradation of organic pollutants in liquid media $[57,58]$. The expected hot injection of electrons during the non-radiative decay of plasmons has been abundantly reported for $\mathrm{Au}-\mathrm{TiO}_{2}$ heterostructures. In the case of $\mathrm{Au}-\mathrm{ZnO}$, the distribution of energy levels, the similarity on the work functions for $\mathrm{Au}$ and $\mathrm{ZnO}$ and the lack of clear influence of multiple synthesis parameters on the final optical response make the prediction of its photocatalytic outcome a challenge to be unveiled.

\subsection{Anisotropic Au-ZnO heteronanostructures: FDTD theoretical simulation}

FDTD simulations were carried out to complete the experimental information retrieved from SR-EELS analysis and help to understand the nature of the photocatalytic enhancement observed upon 365, 405 and $460 \mathrm{~nm}$ light illumination. A wide variety of particle sizes and shapes was systematically simulated, attending to the dispersity observed in 
the real sample by TEM analysis. Thus, gold nanotriangles over a $\mathrm{ZnO}$ support with different gold thickness, varying from 5 to $15 \mathrm{~nm}$, as a function of the excitation wavelength were simulated. Figure $4 \mathrm{a}$ shows a scheme of the simulation model of the 3D finite-difference time-domain (3D-FDTD) simulation of the gold nanotriangles deposited on $\mathrm{ZnO}$. Figure $4 \mathrm{~b}$ shows the average electric field enhancement in the heterojunction $\mathrm{Au}-\mathrm{ZnO}$ as a function of the irradiation wavelengths selected for their positive photo-catalytic response for the three populations of Au nanotriangles. The total enhanced electric field exhibits almost the same magnitude for the three illumination wavelengths, being slightly higher for $405 \mathrm{~nm}$, and the three populations contributing in a similar proportion at each illumination wavelength. Furthermore, in order to better understand the interaction between the irradiation wavelength and the $\mathrm{Au}-\mathrm{ZnO}$ systems, we studied the distribution of the electric field. Figure $4 \mathrm{c}$ illustrates this electric field distribution simulated by 3D-FDTD under 365, 405 and $460 \mathrm{~nm}$ excitation wavelength for gold nanotriangles with $10 \mathrm{~nm}$ of thickness over $\mathrm{ZnO}$ support. The same study was performed for 5 and $15 \mathrm{~nm}$ yielding analogous results (data not shown). The colour scale represents the normalized amplitude of the enhanced electric field $|E|$ with respect to the amplitude of the incoming electric field $\left|E_{0}\right|$. The simulations show the electric field tends to confinement over the apex of the gold nanotriangles in close contact with the $\mathrm{ZnO}$ support as previously revealed by SR-EELS (Figure 2b-2c). Previous calculations available in the literature for triangular-shaped metallic structures have suggested that under vacuum conditions, the electric field exhibits a more or less homogeneous distribution over the three apexes [83, 84]. While those calculations were referred to structures surrounded by an unaltered dielectric environment, our simulations show some discrepancy since $\mathrm{ZnO}$ and its dielectric properties has been additionally taken into consideration. A strong interaction between the $\mathrm{ZnO}$ support and the $\mathrm{Au}$ nanotriangles has been considered. The interaction is based on a charge transfer between the $\mathrm{ZnO}$ with the enhanced electric field located in the 
gold nanotriangles and further supports the closed contact between metal and semiconductor support that can facilitate the formation of electron-hole pairs inside the surface of the $\mathrm{ZnO}$ semiconductor [85]. In our opinion, such a perfect metal-support coupling explains the strong field enhancements at the interfaces as demonstrated both theoretical and experimentally. The discrepancies found between our model and the activation of certain modes observed by SREELS can be indicative of the absence of a perfect metal-support interaction in our real sample as well as other polarization excitation effects. Therefore, the photocatalytic behaviour of our catalyst under the 365, 405 and $460 \mathrm{~nm}$ irradiation wavelengths suggests a coupling between electric field generated by the gold nanotriangles and the $\mathrm{ZnO}$ surface.

a)

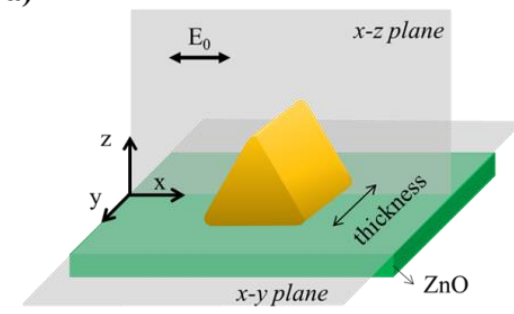

b)

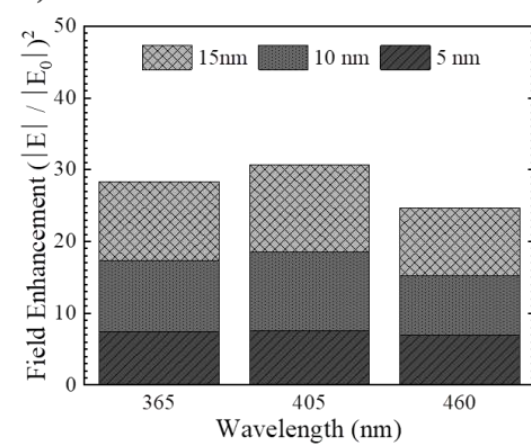

c)

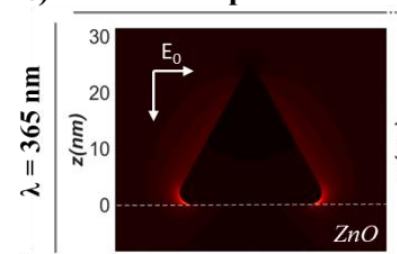

$\mathrm{ZnO}$
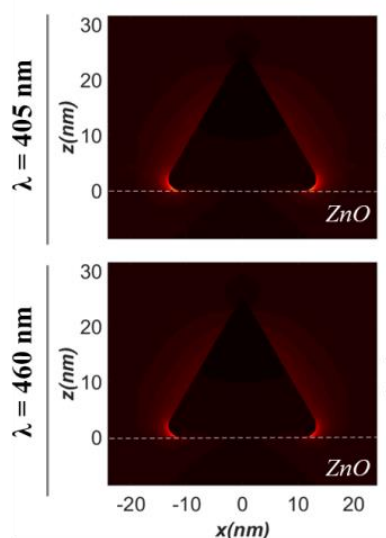

$x-y$ plane

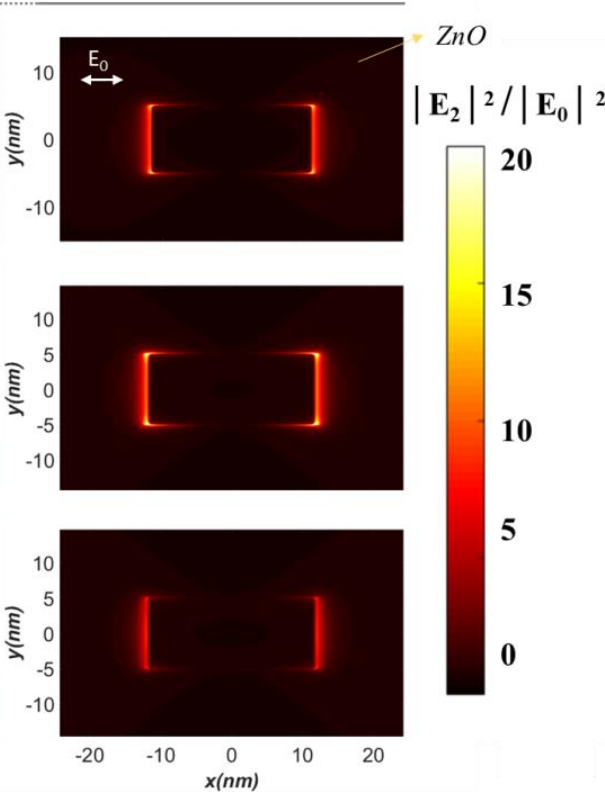

Figure 4. (a) Schematic simulation model of the 3D FDTD simulation of the gold nanotriangles over a $\mathrm{ZnO}$ support; (b) FDTD-simulated electric field enhancement averaged on the gold nanotriangles- $\mathrm{ZnO}$ junction at different excitation wavelengths for three different gold nanotriangles thickness; (c) Colour-code FDTD-simulated image of the electric field intensity distribution for gold nanotriangle with $10 \mathrm{~nm}$ of gold thickness over $\mathrm{ZnO}$ for the three different excitation wavelengths. 


\section{CONCLUSIONS}

Anisotropic $\mathrm{Au}-\mathrm{ZnO}$ photocatalysts based on prisms and triangular-shaped metallic nanostructures have been successfully grown onto $\mathrm{ZnO}$ nanoparticles. The combination of experimental measurements at the nanoscale level by SR-EELS and theoretical approximations suggest a strong interaction at the interface between metal and semiconductor. The LED-driven photooxidation of n-hexane has revealed an enhanced response upon irradiation with the more energetic wavelengths (i.e. UV, violet and blue). This suggests a predominant role of intraband electrons from the metallic nanostructures. The absence of a more positive response in the plasmonic absorption region of the anisotropic gold structure may be suggesting a limited interaction of the catalyst with the adsorbate molecule (i.e. n-hexane). Still, the experimental and simulation results show a promising candidate for multiple photocatalytic reactions of interest in environmental and energy applications.

\section{Acknowledgements}

Financial support from the European Research Council (ERC Advanced Grant CADENCE number 742684) is gratefully acknowledged. We also acknowledge the support from CIBER-BBN and MINECO (Spain) with project CTQ2016-79419-R. R.A. acknowledges funding from the Spanish Ministerio de Ciencia, Innovación y Universidades (project grant MAT2016-79776-P (AEI/FEDER, UE)) and from the European Union H2020 program "ESTEEM3" (823717). The synthesis of materials has been performed by the Platform of Production of Biomaterials and Nanoparticles of the NANOBIOSIS ICTS, more specifically by the Nanoparticle Synthesis Unit of the CIBER in Bioengineering, Biomaterials \& Nanomedicine (CIBER-BBN). The TEM studies were conducted at the 
Laboratorio de Microscopias Avanzadas, Instituto de Nanociencia de Aragon, Universidad de Zaragoza, Spain.

\section{Electronic Supplementary Material}

Supplementary material (PDF) is available in the online version of this article.

\section{Competing financial interests}

The authors declare no competing financial interests.

\section{REFERENCES}

[1] IPCC, Special Report on Emission Scenarios, in: C.U. Press (Ed.), Working Group III of the Intergovernmental Panel on Climate Change, Cambridge, 2018.

[2] Y. Boyjoo, H.Q. Sun, J. Liu, V.K. Pareek, S.B. Wang, Chem. Eng. J. 310 (2017) 537559.

[3] H.B. Huang, Y. Xu, Q.Y. Feng, D.Y.C. Leung, Catal. Sci. Technol. 5 (2015) 26492669.

[4] C. He, J. Cheng, X. Zhang, M. Douthwaite, S. Pattisson, Z.P. Hao, Chem. Rev. 119 (2019) 4471-4568.

[5] K.W. Shah, W.X. Li, Nanomaterials 9 (2019).

[6] E. Gioria, F.A. Marchesini, A. Soldati, A. Giorello, J.L. Hueso, L. Gutierrez, Appl. Sci.-Basel 9 (2019).

[7] M.S. Kamal, S.A. Razzak, M.M. Hossain, Atmos. Environ. 140 (2016) 117-134.

[8] J.L. Hueso, J.P. Espinos, A. Caballero, J. Cotrino, A.R. Gonzalez-Elipe, Carbon 45 (2007) 89-96.

[9] J.L. Hueso, J. Cotrino, A. Caballero, J.P. Espinos, A.R. Gonzalez-Elipe, J. Catal. 247 (2007) 288-297. 
[10] F. Khodadadian, M. Nasalevich, F. Kapteijn, A.I. Stankiewicz, R. Lakerveld, J. Gascon, in: G. Stefanidis, A. Stankiewicz (Eds.), Alternative Energy Sources for Green Chemistry, 2016, pp. 227-269.

[11] T. Van Gerven, G. Mul, J. Moulijn, A. Stankiewicz, Chem. Eng. Process. 46 (2007) 781-789.

[12] F. Khodadadian, M.W. de Boer, A. Poursaeidesfahani, J.R. van Ommen, A.I. Stankiewicz, R. Lakerveld, Chem. Eng. J. 333 (2018) 456-466.

[13] C.J. Bueno-Alejo, J.L. Hueso, R. Mallada, I. Julian, J. Santamaria, Chem. Eng. J. 358 (2019) 1363-1370.

[14] B.M. da Costa, A.L.P. Araujo, G.V. Silva, R.A.R. Boaventura, M.M. Dias, J.C.B. Lopes, V.J.P. Vilar, Chem. Eng. J. 310 (2017) 331-341.

[15] P. Pichat, Appl. Catal. B-Environ. 245 (2019) 770-776.

[16] V.J. Rico, J.L. Hueso, J. Cotrino, V. Gallardo, B. Sarmiento, J.J. Brey, A.R. Gonzalez-Elipe, Chem. Commun. (2009) 6192-6194.

[17] J.L. Hueso, A.R. Gonzalez-Elipe, J. Cotrino, A. Caballero, J. Phys. Chem. A 111 (2007) 1057-1065.

[18] F. Khodadadian, F.G. de la Garza, J.R. van Ommen, A.I. Stankiewicz, R. Lakerveld, Chem. Eng. J. 362 (2019) 375-382.

[19] A. Stankiewicz, F.E. Sarabi, A. Baubaid, P. Yan, H. Nigar, Chem. Rec. 19 (2019) 4050.

[20] H. Nigar, I. Julian, R. Mallada, J. Santamaria, Environ. Sci. Technol. 52 (2018) 58925901.

[21] A.I. Stankiewicz, P. Yan, Ind. Eng. Chem. Res. 58 (2019) 9212-9222.

[22] S.H. Moreno, A.I. Stankiewicz, G.D. Stefanidis, React. Chem. Eng. 4 (2019) 12531269. 
[23] X.X. Xu, P.T. Wang, W.C. Xu, J.L. Wu, L.M. Chen, M.L. Fu, D.Q. Ye, Chem. Eng. J. 283 (2016) 276-284.

[24] D. Dobslaw, A. Schulz, S. Helbich, C. Dobslaw, K.H. Engesser, J. Environ. Chem. Eng. 5 (2017) 5501-5511.

[25] J.L. Hueso, A.R. Gonzalez-Elipe, J. Cotrino, A. Caballero, J. Phys. Chem. A 109 (2005) 4930-4938.

[26] S. Sarina, E.R. Waclawik, H.Y. Zhu, Green Chem. 15 (2013) 1814-1833.

[27] A.O. Govorov, H. Zhang, H.V. Demir, Y.K. Gun'ko, Nano Today 9 (2014) 85-101.

[28] S. Linic, U. Aslam, C. Boerigter, M. Morabito, Nat. Mater. 14 (2015) 567-576.

[29] S. Linic, P. Christopher, D.B. Ingram, Nat. Mater. 10 (2011) 911-921.

[30] M.C. Ortega-Liebana, J.L. Hueso, S. Ferdousi, R. Arenal, S. Irusta, K.L. Yeung, J. Santamaria, Appl. Catal. B-Environ. 218 (2017) 68-79.

[31] H.F. Cheng, K. Fuku, Y. Kuwahara, K. Mori, H. Yamashita, J. Mater. Chem. A 3 (2015) 5244-5258.

[32] J.Y. Li, W. Cui, P. Chen, X.A. Dong, Y.H. Chu, J.P. Sheng, Y.X. Zhang, Z.M. Wang, F. Dong, Appl. Catal. B-Environ. 260 (2020).

[33] J.Y. Li, X.A. Dong, G. Zhang, W. Cui, W.L. Cen, Z.B. Wu, S.C. Lee, F. Dong, J. Mater. Chem. A 7 (2019) 3366-3374.

[34] X.A. Dong, W. Cui, H. Wang, J.Y. Li, Y.J. Sun, H.N. Wang, Y.X. Zhang, H.W. Huang, F. Dong, Sci. Bull. 64 (2019) 669-678.

[35] J. Graus, C.J. Bueno-Alejo, J.L. Hueso, Catalysts 8 (2018) 16.

[36] M. Zieba, J.L. Hueso, M. Arruebo, G. Martinez, J. Santamaria, New J. Chem. 38 (2014) 2037-2042.

[37] L. Gomez, J.L. Hueso, M.C. Ortega-Liebana, J. Santamaria, S.B. Cronin, Catal. Commun. 56 (2014) 115-118. 
[38] Y.F. Huang, M. Zhang, L.B. Zhao, J.M. Feng, D.Y. Wu, B. Ren, Z.Q. Tian, Angew. Chem.-Int. Edit. 53 (2014) 2353-2357.

[39] L. Ma, S. Chen, Y. Shao, Y.L. Chen, M.X. Liu, H.X. Li, Y.L. Mao, S.J. Ding, Catalysts 8 (2018).

[40] S. Linic, P. Christopher, H.L. Xin, A. Marimuthu, Accounts Chem. Res. 46 (2013) 1890-1899.

[41] U. Aslam, V.G. Rao, S. Chavez, S. Linic, Nat. Catal. 1 (2018) 656-665.

[42] J. Gargiulo, R. Berte, Y. Li, S.A. Maier, E. Cortes, Accounts Chem. Res. 52 (2019) $2525-2535$.

[43] D. Glass, E. Cortes, S. Ben-Jaber, T. Brick, W.J. Peveler, C.S. Blackman, C.R. Howle, R. Quesada-Cabrera, I.P. Parkin, S.A. Maier, Adv. Sci. (In press).

[44] F. Dieleman, M.S. Tame, Y. Sonnefraud, M.S. Kim, S.A. Maier, Nano Lett. 17 (2017) $7455-7461$.

[45] E. Cortes, W. Xie, J. Cambiasso, A.S. Jermyn, R. Sundararaman, P. Narang, S. Schlucker, S.A. Maier, Nat. Commun. 8 (2017).

[46] D.L. Mack, E. Cortes, V. Giannini, P. Torok, T. Roschuk, S.A. Maier, Nat. Commun. 8 (2017).

[47] N.J. Halas, S. Lal, W.S. Chang, S. Link, P. Nordlander, Chem. Rev. 111 (2011) 39133961.

[48] M.L. Brongersma, N.J. Halas, P. Nordlander, Nat. Nanotechnol. 10 (2015) 25-34.

[49] L.A. Zhou, D.F. Swearer, C. Zhang, H. Robatjazi, H.Q. Zhao, L. Henderson, L.L. Dong, P. Christopher, E.A. Carter, P. Nordlander, N.J. Halas, Science 362 (2018) 69-+.

[50] N. Udawatte, M. Lee, J. Kim, D. Lee, ACS Appl. Mater. Interfaces 3 (2011) 45314538. 
[51] S. Kim, Y. Yu, S.Y. Jeong, M.G. Lee, H.W. Jeong, Y.M. Kwon, J.M. Baik, H. Park, H.W. Jang, S. Lee, Catal. Sci. Technol. 8 (2018) 3759-3766.

[52] C.G. Silva, M.J. Sampaio, S.A.C. Carabineiro, J.W.L. Oliveira, D.L. Baptista, R. Bacsa, B.F. Machado, P. Serp, J.L. Figueiredo, A.M.T. Silva, J.L. Faria, J. Catal. 316 (2014) 182-190.

[53] M. Sabbaghan, A. Ghalaei, J. Mol. Liq. 193 (2014) 116-122.

[54] W. Xie, Y.Z. Li, W. Sun, J.C. Huang, H. Xie, X.J. Zhao, J. Photochem. Photobiol. AChem. 216 (2010) 149-155.

[55] G.L. Hallett-Tapley, M.J. Silvero, C.J. Bueno-Alejo, M. Gonzalez-Bejar, C.D. McTiernan, M. Grenier, J.C. Netto-Ferreira, J.C. Scaiano, J. Phys. Chem. C 117 (2013) $12279-12288$

[56] L. Ma, S.J. Ding, Mater. Lett. 217 (2018) 255-258.

[57] R. Kavitha, S.G. Kumar, Mater. Sci. Semicond. Process 93 (2019) 59-91.

[58] O.K. Ranasingha, C.J. Wang, P.R. Ohodnicki, J.W. Lekse, J.P. Lewis, C. Matranga, J. Mater. Chem. A 3 (2015) 15141-15147.

[59] J. Li, J.L. Wang, Z.H. Dai, H.B. Li, Talanta 176 (2018) 428-436.

[60] P. She, K.L. Xu, Y.X. Shang, Q.R. He, S. Zeng, S.Y. Yin, G.L. Lu, S. Liang, H. Sun, Z.N. Liu, New J. Chem. 42 (2018) 3315-3321.

[61] A. Nezamzadeh-Ejhieh, S. Khorsandi, J. Ind. Eng. Chem. 20 (2014) 937-946.

[62] B. Bottega-Pergher, J. Graus, C.J. Bueno-Alejo, J.L. Hueso, Eur. J. Inorg. Chem. (2019) 3228-3234.

[63] N. Gogurla, A.K. Sinha, S. Santra, S. Manna, S.K. Ray, Sci Rep 4 (2014).

[64] M.J. Sampaio, J.W.L. Oliveira, C.I.L. Sombrio, D.L. Baptista, S.R. Teixeira, S.A.C. Carabineiro, C.G. Silva, J.L. Faria, Appl. Catal. A-Gen. 518 (2016) 198-205. 
[65] C.J. Wang, O. Ranasingha, S. Natesakhawat, P.R. Ohodnicki, M. Andio, J.P. Lewis, C. Matranga, Nanoscale 5 (2013) 6968-6974.

[66] R. Arenal, F. de la Pena, O. Stephan, M. Walls, M. Tence, A. Loiseau, C. Colliex, Ultramicroscopy 109 (2008) 32-38.

[67] C. Jeanguillaume, C. Colliex, Ultramicroscopy 28 (1989) 252-257.

[68] O. Nicoletti, F. de la Pena, R.K. Leary, D.J. Holland, C. Ducati, P.A. Midgley, Nature 502 (2013) 80-+.

[69] E. Palik, Handbook of Optical Constants of Solids, 2007, pp. xiii-xv.

[70] M.R. Querry, Optical Constants, University of Missouri, Kansas, 1985.

[71] L. Chen, F. Ji, Y. Xu, L. He, Y.F. Mi, F. Bao, B.Q. Sun, X.H. Zhang, Q. Zhang, Nano Lett. 14 (2014) 7201-7206.

[72] S. Kuriakose, K. Sahu, S.A. Khan, A. Tripathi, D.K. Avasthi, S. Mohapatra, Opt. Mater. 64 (2017) 47-52.

[73] E. Petryayeva, U.J. Krull, Anal. Chim. Acta 706 (2011) 8-24.

[74] R. Arenal, L. Henrard, L. Roiban, O. Ersen, J. Burgin, M. Treguer-Delapierre, J. Phys. Chem. C 118 (2014) 25643-25650.

[75] J.J. Armao, I. Nyrkova, G. Fuks, A. Osypenko, M. Maaloum, E. Moulin, R. Arenal, O. Gavat, A. Semenov, N. Giuseppone, J. Am. Chem. Soc. 139 (2017) 2345-2350.

[76] H.Y. Feng, F. Luo, R. Arenal, L. Henrard, F. Garcia, G. Armelles, A. Cebollada, Nanoscale 9 (2017) 37-44.

[77] M. Kociak, O. Stephan, Chem. Soc. Rev. 43 (2014) 3865-3883.

[78] M. Prieto, R. Arenal, L. Henrard, L. Gomez, V. Sebastian, M. Arruebo, J. Phys. Chem. C 118 (2014) 28804-28811. 
[79] A. Losquin, L.F. Zagonel, V. Myroshnychenko, B. Rodriguez-Gonzalez, M. Tence, L. Scarabelli, J. Forstner, L.M. Liz-Marzan, F.J.G. de Abajo, O. Stephan, M. Kociak, Nano Lett. 15 (2015) 1229-1237.

[80] G. Bertoni, F. Fabbri, M. Villani, L. Lazzarini, S. Turner, G. Van Tendeloo, D. Calestani, S. Gradecak, A. Zappettini, G. Salviati, Sci Rep 6 (2016).

[81] L. Uson, M.G. Colmenares, J.L. Hueso, V. Sebastian, F. Balas, M. Arruebo, J. Santamaria, Catal. Today 227 (2014) 179-186.

[82] H. Suarez, A. Ramirez, C.J. Bueno-Alejo, J.L. Hueso, Materials 12 (2019).

[83] G. Das, E. Battista, G. Manzo, F. Causa, P.A. Netti, E. Di Fabrizio, ACS Appl. Mater. Interfaces 7 (2015) 23597-23604.

[84] J.M. Kontio, J. Simonen, J. Tommila, M. Pessa, Microelectron. Eng. 87 (2010) 1711 1715.

[85] Z.W. Liu, W.B. Hou, P. Pavaskar, M. Aykol, S.B. Cronin, Nano Lett. 11 (2011) 1111 1116. 